\title{
Effects of Using Seawater and Recycled Coarse Aggregates on Plain Concrete Characteristics
}

\author{
Adel Younis \\ adel.younis@qu.edu.qa \\ Department of Civil and Architectural Engineering, Qatar University, Doha, Qatar \\ Usama Ebead \\ uebead@qu.edu.qa \\ Department of Civil and Architectural Engineering, Qatar University, Doha, Qatar
}

\begin{abstract}
Using seawater and/or recycled coarse aggregates (RCA) for concrete mixing is deemed advantageous from a sustainability perspective. This paper reports on the results of an experimental study on fresh and hardened properties of concrete mixed with seawater and RCA. Three concrete mixtures were investigated, namely, Mix A (traditional concrete), Mix B (concrete made with seawater), and Mix C (concrete made with seawater and RCA). It was concluded that the use of seawater and/or RCA had a notable effect on fresh concrete properties. Mix B concrete showed a slightly lower strength performance than that of Mix A $(<15 \%)$, whereas the strength of Mix C concrete had a significant drop $(\sim 30 \%)$ compared to the reference (Mix A). The permeability performance of hardened concrete for Mixes A and B was similar, whereas Mix C concrete showed $60 \%$ increase in water absorption and $100 \%$ increase in chloride permeability as compared to Mix A.
\end{abstract}

Keywords: Sustainable Concrete; Seawater concrete; Recycled concrete aggregate; Workability; Strength; Permeability

\section{INTRODUCTION}

Concrete is the most commonly used construction material worldwide (Monteiro \& Miller, 2017), whose production from its traditional raw ingredients typically results in negative impacts on the environment (Miller et al., 2016). Recently, there has been an increasing interest in other sources of concrete mixing ingredients so as to achieve more "green" concrete (Alnahhal \& Aljidda, 2018; Rahal, 2007). In this context, seawater and recycled coarse aggregate (RCA) have increasingly emerged as alternative mixing ingredients for concrete, bearing in mind the increasing global concerns of freshwater scarcity (Mekonnen \& Hoekstra, 2016), the accumulation of construction and demolition waste, as well as the possible depletion of natural aggregate resources (Tam et al., 2018). However, steel reinforcement corrosion potentially associated with such concrete mixtures (as a result of seawater chloride ions) makes an undeniable challenge that mitigates the use of seawater in concrete. Yet, this can be basically addressed by using the proposed mixtures in non-reinforced concrete applications or with the use of non-corrosive reinforcement in concrete structures (Younis et al., 2018a). Given that, the current paper reports on the results of an experimental campaign carried out to investigate the effects of using seawater and RCA in concrete. The paper establishes a comparison among three concrete mixtures, namely, (i) Mix A (reference), which 
represents the conventional mix produced with freshwater and natural coarse aggregate (NCA); (ii) Mix B, which is produced with seawater and NCA; and (iii) Mix C, which is produced with seawater and RCA.

\section{EXPERIMENTATION}

\subsection{Materials}

Seawater was brought from Al-Khor coastal area in Qatar to be used for concrete mixing. Chemical characterization test results obtained for the two water types can be found in (Younis et al., 2018b). The negative effects of seawater mixing are expected to arise due to the high presence of sulfate and chloride ions: the concentration of these ions in seawater was higher than the allowable limits for concrete production. As for fine aggregates, washed sand was used in all concrete mixtures. As for coarse aggregates, Gabbro crushed rock was used in Mixes A and B. Recycled coarse aggregates - that are often produced in Qatar from demolished concrete structures (Al-Ansary \& Iyengar, 2013) - were used in Mix C. Physical and mechanical characterization test results obtained for the aggregates used can be found in (Younis et al., 2020). In general, RCAs showed higher water absorption as well as lower density and mechanical strength compared to NCAs, which can be basically attributed to the adhered porous mortar on the surface. As for cementitious materials, ordinary Portland cement (OPC) and blast furnace slag (at 65\% replacement level) were used in all concrete mixtures. The use of slag is actually known to improve the performance of concrete mixed with seawater or RCA (Etxeberria et al., 2016). Chemical characterization test results obtained for both cementitious materials can be found in (Younis et al., 2018b).

\subsection{Concrete Mixture Proportions}

Ready-mix concrete with a 60-MPa 28-day design compressive strength was used to cast the test specimens. The mix design proportions for concrete mixtures (as per BS EN 206) are presented in Table 1. As shown in the table, the mix proportions were the same for Mixes A and B (i.e., the difference was only in the water type). In Mix C, natural coarse aggregates were fully replaced by RCAs on a volume basis. Additional mixing water was considered in Mix $\mathrm{C}$ in order to account for the higher water absorption of RCAs. A commercial superplasticizer was incorporated with a $3.8-\mathrm{kg} / \mathrm{m}^{3}$ dosage in all concrete mixtures.

Table 1: Concrete Mixture Proportions (as $\mathrm{kg} / \mathrm{m}^{3}$ of Concrete).

\begin{tabular}{|l|c|c|c|}
\hline Constituent & Mix A & Mix B & Mix C \\
\hline OPC & 158 & 158 & 158 \\
\hline Slag & 292 & 292 & 292 \\
\hline Gabbro 20 mm & 700 & 700 & - \\
\hline Gabbro 10 mm & 490 & 490 & - \\
\hline 5-20 mm RCA & - & - & 990 \\
\hline Washed sand & 750 & 750 & 750 \\
\hline Freshwater & 165 & - & - \\
\hline Seawater & - & 165 & 205 \\
\hline
\end{tabular}




\subsection{Assessment Methods for Concrete}

Physical characteristics and workability performance of fresh concrete were compared among the three mixtures. For this, two tests were performed: (a) slump flow test as per ASTM C143, and (b) density, yield, and air content tests as per ASTM C138. As for hardened concrete, compressive strength test was conducted on concrete cylinders (150 by $300 \mathrm{~mm}$ ) as per ASTM C39 considering two test variables: (i) concrete mixture (A, $\mathrm{B}$, or C); and (ii) test time (Days 3, 7, 28, or 56 following mixing). Moreover, rapid chloride permeability (RCP) test was performed as per ASTM C1202 to measure the chloride penetration resistance of hardened concrete. Also, water absorption (WA) test was conducted according to BS 1881-122, to measure the water ingress through the concrete surface.

\section{RESULTS AND DISCUSSIONS}

\subsection{Fresh Concrete}

Table 2 presents the density, yield, and air content measurements for the three concrete mixtures. As intuitively expected, the measured density of fresh concrete for Mix A and Mix B was the same $\left(2555 \mathrm{~kg} / \mathrm{m}^{3}\right)$. However, the density of Mix C concrete $(2400 \mathrm{~kg} /$ $\mathrm{m}^{3}$ ) was approximately $5 \%$ lower than that of Mixes A and B. Using $100 \%$ RCA in Mix $\mathrm{C}$ reduced the concrete density: this is attributed to the RCAs being naturally less dense than NCAs as a result of the adhered porous mortar on their surface (Behera et al., 2014). Previous studies concerning recycled-aggregate concrete conform with the results herein (Silva et al., 2018), showing around 5-8\% inferior density of concrete as a result of using $100 \%$ RCA.

As shown in Table 2, a slight increase in the air content was observed on the fresh concrete while mixing with seawater (1.40\% for Mix A and $1.65 \%$ for Mix B). However, combining seawater and RCA in Mix C resulted in a notable increase in the air content (more than 30\%) as compared to that of the conventional Mix A. In principle, RCAs have higher porosity as well as rougher surface caused by recycling processes (Silva et al., 2018) and therefore, air could have easily become trapped in the aggregates' surface. Bearing in mind the fact that RCAs were not pre-saturated in this study, it is possible that the test method has measured the additional part of the air content inside the RCA.

Table 2: Physical Characteristics of Fresh Concrete.

\begin{tabular}{|l|c|c|c|}
\hline Characteristic & Mix A & Mix B & Mix C \\
\hline Density & $\mathrm{kg} / \mathrm{m}^{3} 2555$ & $\mathrm{~kg} / \mathrm{m}^{3} 2555$ & $\mathrm{~kg} / \mathrm{m}^{3} 2400$ \\
\hline Yield & $101.6 \%$ & $101.6 \%$ & $99.9 \%$ \\
\hline Air content & $1.4 \%$ & $1.65 \%$ & $1.85 \%$ \\
\hline
\end{tabular}

Figure 1 depicts the slump flow versus the time elapsed for concrete mixtures. As shown in the figure, the use of seawater in Mix B reduced the slump flow of fresh concrete to be (initially) $20 \%$ lower than that of Mix A. Using seawater also led to lower slump retention, where the slump loss in Mix B was faster than that of Mix A. However, combining seawater and recycled coarse aggregates in Mix $\mathrm{C}$ resulted in a more significant reduction in the workability of the resulted concrete. Not only did the 
concrete of Mix C show an initial slump 25\% lower than that of Mix A, but also it remained flowable for only half the period (i.e., 60 minutes in Mix $\mathrm{C}$ versus 120 minutes in Mixes A and B).

The reduction in workability of Mix B concrete can be attributed to the accelerating effects induced by seawater ions ( $\mathrm{Li}$ et al., 2019). As for Mix C, incorporating RCA resulted in a slump loss greater than that of Mix B. In principle, RCAs have harsh/ granular texture (due to crushing of parent concrete) as well as higher porosity (because of the adhered porous mortar on the surface). Accordingly, more water (or energy) is required for compaction on account of the inter-particle friction (Behera et al., 2014).

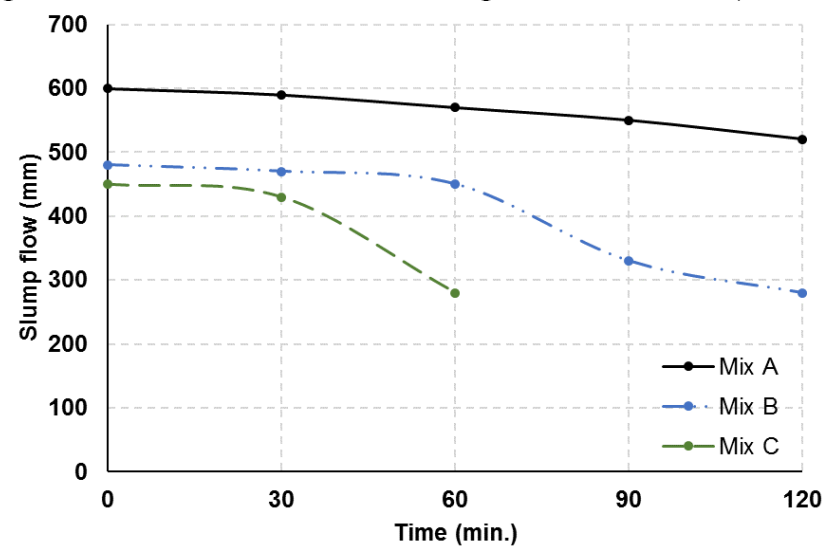

Figure 1: Slump Flow Measurements as a Function of Time.

\subsection{Hardened Concrete}

Figure 2 depicts the compressive strength results for concrete mixtures. Comparing Mix A and Mix B concretes, a slight increase (3-5\%) was generally observed in the compressive strength at early age (i.e., up to 7 days) with the use of seawater. This higher early-age strength of Mix B concrete can be connected with its lower porosity due to the acceleration of cement hydration (Kaushik \& Islam, 1995). However, at later ages (i.e., 28 days or later), Mix B showed compressive strength lower than that of Mix A, with an approximate difference of 7-10\% reported at Day 56. Kaushik \& Islam (1995) suggested that the lower long-term strength of seawater concrete can be attributed to the leaching of hydration products.

Mix C, however, showed lower compressive strength compared to the other two mixtures at all ages. As of Day 56, the compressive strength of Mix C concrete was $\sim 30 \%$ lower than that of the conventional Mix A. The negative effects from seawater and RCA were simultaneously combined in Mix $\mathrm{C}$ and reflected on its strength performance. In principle, recycled aggregate concrete is more likely to have lower strength performance due to the inferior mechanical performance of RCA as well as the weak interfacial bond between RCA and the matrix (Rahal \& Alrefaei, 2017, 2018)such as the shear resistance. This paper presents the results of an experimental investigation of the effects of the use of RCA on the shear strength of longitudinally reinforced concrete (RC.

The 28-day and 56-day results for RCP and WA tests are presented in Table 3. In general, the test results showed a higher permeability performance of 56-day hardened 
concrete than that reported at Day 28, mostly because of improvements in concrete due to the ongoing hydration. RCP test results for all concretes lied within the acceptable limits as per Qatar Construction Specifications (QCS, 2014). However, WA test results revealed a deprived permeability performance for Mix C compared to the other two mixtures or even the standard limits $-2.5 \%$ max. as per (QCS, 2014).

Whilst seawater mixing showed almost no effect on the permeability performance of hardened concrete (results of Mixes A and B were comparable for all tests), incorporating RCA in Mix C had evidently reduced its permeability performance. This indeed is attributed to the high porosity of RCA that makes concrete more susceptible to permeation (Guo et al., 2018).

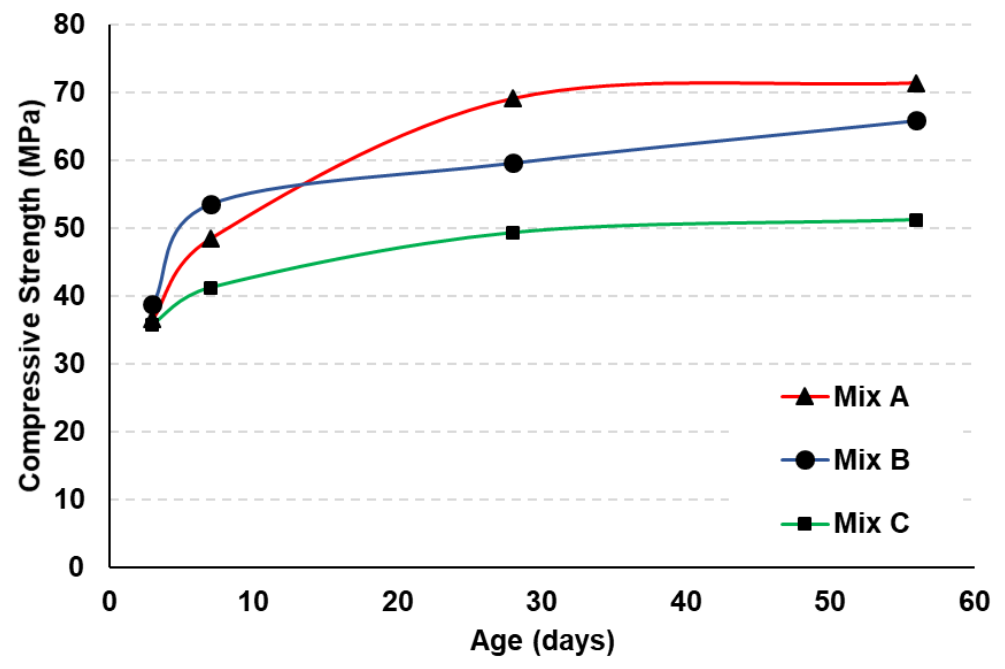

Figure 2: Compressive Strength Results.

Table 3: Summary of Permeability Test Results.

\begin{tabular}{|c|c|c|}
\hline Specimen & $\begin{array}{c}\text { RCP (as charge } \\
\text { (passed in coulombs }\end{array}$ & (\%) WA \\
\hline Mix A-28d & 407 & 1.79 \\
\hline Mix A-56d & 369 & 1.58 \\
\hline Mix B - 28d & 439 & 1.69 \\
\hline Mix B - 56d & 349 & 1.56 \\
\hline Mix C-28d & 1100 & 2.87 \\
\hline Mix C-56d & 844 & 2.63 \\
\hline
\end{tabular}

\section{CONCLUSION}

This paper compared three concrete mixtures, namely, Mix A (conventional concrete), Mix B (seawater-mixed concrete), and Mix C (seawater-mixed recycled-aggregate concrete). Based on the results of this study, the following conclusions were drawn:

- The concrete density and air content did no notably change with seawater mixing. However, using $100 \%$ seawater and RCA reduced the concrete density (by $\sim 5 \%$ ) and 
increased the air-content measurements of Mix C.

- Seawater mixing led to a noticeable reduction in the slump flow of fresh concrete ( 20\%). Using 100\% seawater and RCA in Mix C led to a more significant decrease in the slump flow $(\sim 25 \%)$ as well as the workability retention.

- Seawater mixing initially led to a slight increase in strength performance (till Day 7 ), followed by a reduction of $7-10 \%$ in the long term. Combining seawater and $\mathrm{RCA}$ in Mix $\mathrm{C}$, however, resulted in a significant reduction in strength performance of concrete $(\sim 30 \%)$.

- Seawater mixing showed almost no effect on the permeability performance of hardened concrete. However, using 100\% seawater and RCA in Mix C led to a significantly reduced permeability performance.

\section{ACKNOWLEDGMENT}

The authors would like to acknowledge the fund received by the NPRP grant \# NPRP 9-110-2-052 from Qatar National Research Fund (a member of Qatar Foundation). The findings of this study are solely the responsibility of the authors. The authors would like to thank Readymix Qatar (as a part of LafargeHolcim) for providing the expertise that greatly helped in completing this research.

\section{REFERENCES}

Al-Ansary, M. \& Iyengar, S. R. (2013). Physiochemical characterization of coarse aggregates in Qatar for construction industry. International Journal of Sustainable Built Environment, 2(1), 27-40.

Alnahhal, W. \& Aljidda, O. (2018). Flexural behavior of basalt fiber reinforced concrete beams with recycled concrete coarse aggregates. Construction and Building Materials, Elsevier Ltd, $169,165-178$.

Behera, M., Bhattacharyya, S. K., Minocha, A. K., Deoliya, R. \& Maiti, S. (2014). Recycled aggregate from C\&D waste \& its use in concrete - A breakthrough towards sustainability in construction sector: A review. Construction and Building Materials, 68, 501-516.

Etxeberria, M., Gonzalez-Corominas, A. \& Pardo, P. (2016). Influence of seawater and blast furnace cement employment on recycled aggregate concretes' properties. Construction and Building Materials, 115, 496-505.

Guo, H., Shi, C., Guan, X., Zhu, J., Ding, Y., Ling, T. C., Zhang, H. \& Wang, Y. (2018). Durability of recycled aggregate concrete - A review. Cement and Concrete Composites, 89, 251-259.

Kaushik, S. K. \& Islam, S. (1995). Suitability of sea water for mixing structural concrete exposed to a marine environment. Cement and Concrete Composites, 17(3), 177-185.

Li, L. G., Chen, X. Q., Chu, S. H., Ouyang, Y. \& Kwan, A. K. H. (2019). Seawater cement paste: Effects of seawater and roles of water film thickness and superplasticizer dosage. Construction and Building Materials, 229, 116862.

Mekonnen, M. M. \& Hoekstra, A. Y. (2016). Four billion people facing severe water scarcity. Science Advances, 2(2), e1500323.

Miller, S. A., Horvath, A. \& Monteiro, P. J. M. (2016). Readily implementable techniques can cut annual CO2 emissions from the production of concrete by over $20 \%$. Environmental Research Letters, IOP Publishing, 11(7), 74029. 
Monteiro, P. J. M. \& Miller, S. A. (2017). Towards sustainable concrete. Nature Materials, 16(7), 698-699.

QCS. (2014). Qatar Construction Specifications. Qatar General Organization for Standards and Metrology, Qatar.

Rahal, K. (2007). Mechanical properties of concrete with recycled coarse aggregate. Building and Environment, 42(1), 407-415.

Rahal, K. N. \& Alrefaei, Y. T. (2017). Shear strength of longitudinally reinforced recycled aggregate concrete beams. Engineering Structures, 145, 273-282.

Rahal, K. N. \& Alrefaei, Y. T. (2018). Shear strength of recycled aggregate concrete beams containing stirrups. Construction and Building Materials, 191, 866-876.

Silva, R. V., De Brito, J. \& Dhir, R. K. (2018). Fresh-state performance of recycled aggregate concrete: A review. Construction and Building Materials, 178, 19-31.

Tam, V. W. Y., Soomro, M. \& Evangelista, A. C. J. (2018). A review of recycled aggregate in concrete applications (2000-2017). Construction and Building Materials, 172, 272-292.

Younis, A., Ebead, U. \& Judd, S. (2018a). Life cycle cost analysis of structural concrete using seawater, recycled concrete aggregate, and GFRP reinforcement. Construction and Building Materials, Elsevier, 175, 152-160.

Younis, A., Ebead, U., Suraneni, P. \& Nanni, A. (2018b). Fresh and hardened properties of seawater-mixed concrete. Construction and Building Materials, 190(C), 276-286.

Younis, A., Ebead, U., Suraneni, P. \& Nanni, A. (2020). Performance of sewater-mixed recycledaggregate concrete. Journal of Materials in Civil Engineering, 32(1), 04019331. 